\title{
Clinical outcomes of different surgical approaches for proximal descending thoracic aneurysm involving the distal arch
}

Hyun-Chel Joo, MD, Young-Nam Youn, MD, PhD, Seung-Hyun Lee, MD, PhD, Sak Lee, MD, PhD, Byung-Chul Chang, MD, PhD, and Kyung-Jong Yoo, MD, PhD

\section{ABSTRACT}

Background: The aim of this study was to evaluate clinical outcomes of different approaches to patients with proximal descending thoracic aneurysm (DTA) involving the distal arch.

Methods: From January 2002 to December 2016, 229 consecutive patients with proximal descending aorta aneurysm involving the distal arch underwent surgery using different approaches: total arch and DTA replacement via sternotomy (TAR group; $\mathrm{n}=98$ ), hemiarch and DTA replacement via thoracotomy (DTR group; $n=84$ ), or hybrid arch repair (HAR group; $n=47$ ). We retrospectively evaluated the outcomes of the 3 groups with a mean follow-up duration of 60.2 months.

Results: The in-hospital mortality rate was 3.1\% (3/98) in the TAR group, 11.9\% $(10 / 84)$ in the DTR group, and $4.3 \%(2 / 47)$ in the HAR group $(P=.04)$. The TAR group had a lower incidence of stroke $(3.1 \%, 3 / 98)$ compared with the DTR $(13.1 \%, 11 / 84)$ and HAR $(10.6 \%, 5 / 47)$ groups $(P=.03)$. The overall survival rate at 10 years was $82.8 \% \pm 5.6 \%$ for the TAR group, $61.0 \% \pm 8.6 \%$ for the DTR group, and $55.9 \% \pm 9.0 \%$ for the HAR group (vs DTR $[P=.03]$ and HAR $[P<.01])$. The freedom from composite of aortic events at 10 years was $75.6 \% \pm 8.1 \%$ in the TAR group, $43.6 \% \pm 14.9 \%$ in the DTR group, and $31.1 \% \pm 11.5 \%$ in the HAR group $(P<.01)$.

Conclusions: The sternotomy approach showed better outcomes in terms of operative mortality, stroke, and long-term survival compared with the thoracotomy or hybrid approaches. This study suggests that the sternotomy approach is the superior option for patients with proximal descending aneurysm involving the distal arch. (J Thorac Cardiovasc Surg 2018;155:2289-98)

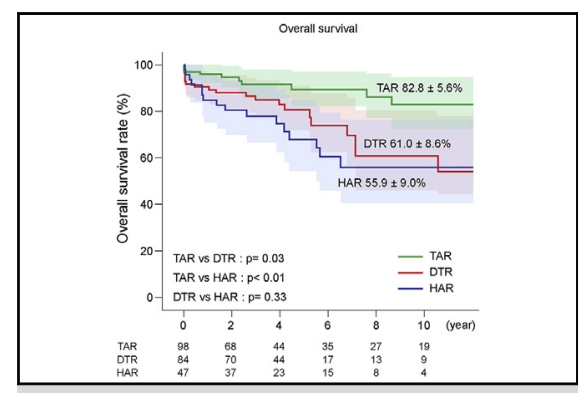

Sternotomy approach has better outcomes compared with thoracotomy or hybrid approaches.

\section{Central Message}

Sternotomy approach is a superior option for patients with proximal DTA involving the distal arch compared to thoracotomy or hybrid approach.

Perspective

The TAR group had better outcomes in terms of operative mortality, stroke, and long-term survival compared with the thoracotomy or hybrid groups. Hybrid repair remains controversial regarding perioperative stroke and long-term durability. Our results suggest that the sternotomy approach is the superior option for patients with proximal DTA involving the distal arch.

See Editorial Commentary page 2299.
Operative techniques for descending thoracic aortic pathologies involving arch have undergone an evolution over the last 3 decades. ${ }^{1,2}$ Particularly for cases of proximal descending thoracic aneurysm (DTA) involving the distal arch, 3 approaches have been introduced: total arch

\footnotetext{
From the Division of Cardiovascular Surgery, Severance Cardiovascular Hospital, Yonsei University College of Medicine, Yonsei University Health System, Seoul, Republic of Korea.

Received for publication July 23, 2017; revisions received Dec 12, 2017; accepted for publication Dec 30, 2017; available ahead of print March 14, 2018.

Address for reprints: Hyun-Chel Joo, MD, Division of Cardiovascular Surgery, Severance Cardiovascular Hospital, Yonsei University College of Medicine, Yonsei University Health System, Seoul, Republic of Korea, (120-752) 250 Seongsanno, Seodaemun-gu, Seoul, Korea (E-mail: vietcomm@yuhs.ac).

$0022-5223 / \$ 36.00$

Copyright (c) 2018 by The American Association for Thoracic Surgery

https://doi.org/10.1016/j.jtcvs.2017.12.152
}

replacement via sternotomy, hemiarch replacement via thoracotomy, and a hybrid approach. ${ }^{3-5}$ Each technique has merit and demerit, and the superior option has not been established.

The thoracotomy approach allows a sufficient view of the distal lesion, but it requires risky procedures, such as arch clamping or deep hypothermic circulatory arrest, to achieve proximal anastomosis. Moreover, this approach requires lung manipulation and can cause severe pain from the

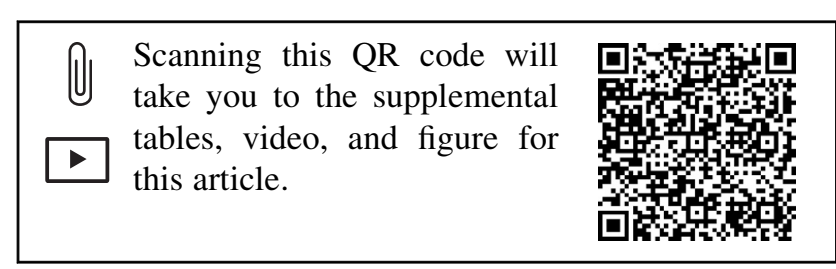




\section{Abbreviations and Acronyms \\ $\mathrm{CPB}=$ cardiopulmonary bypass \\ DTA = descending thoracic aneurysm \\ DTR $=$ DTA replacement via thoracotomy \\ HAR = hybrid arch repair \\ LSCA = left subclavian artery \\ $\mathrm{rSO} 2=$ regional $\mathrm{SO} 2$ \\ TAR = total arch and DTA replacement via sternotomy \\ TEVAR $=$ thoracic endovascular aortic repair}

thoracotomy incision, which can lead to pulmonary complications. Conversely, the sternotomy approach has the advantages of avoiding lung manipulation and arch clamping. However, in cases of deep distal lesions, this approach fails to secure a clear view to perform sutures on a distal anastomosis site. As an attractive alternative to open repair, the hybrid procedure combines debranching of supra-aortic branch vessels with stent grafting of the aortic arch. Although several studies examining the hybrid approach have reported encouraging results, the safety of the procedure and long-term durability remain unclear because of complications associated with angulated morphology and involvement of supra-aortic vessels and reintervention. ${ }^{6}$

No previous studies to date have compared these 3 approaches at the same time, focusing on proximal DTA involving the distal arch. It is not clear which is the superior option for treating this type of aortic lesion. Thus, the aim of this study was to compare the clinical outcomes of these different treatment approaches for aortic pathologies with proximal DTA involving the distal arch.

\section{PATIENTS AND METHODS Patients}

From January 2002 to December 2016, 332 patients underwent surgical repair for descending aortic pathology involving the distal arch at the Yonsei Cardiovascular Hospital of Yonsei University Health System in Seoul, Korea. We excluded patients with type A dissection, Valsalva aneurysm, concomitant valve or coronary bypass surgery, distal descending (below the carina level T7) or thoracoabdominal aneurysm. After the exclusion process, 229 patients who underwent aortic repair using different approaches were enrolled in the study. Ninety-eight patients $(42.8 \%)$ underwent total arch and proximal DTA replacement via sternotomy (TAR group), 84 patients $(36.7 \%)$ underwent hemiarch and DTA replacement via thoracotomy (DTR group), and 47 patients $(20.5 \%)$ underwent hybrid aortic repair (HAR group; Figure 1). The hybrid group included patients who underwent hybrid arch repair with supra-aortic branch revascularization (debranching) involving at least one common carotid artery bypass and simultaneous or staged endovascular thoracic stent grafting. The 229 procedures in this study were performed by 4 different surgeons. The selection of the type of approach method was primarily decided at the discretion of the multidisciplinary team. Hybrid arch repair was performed with increasing frequency by some surgeons from 2008 to 2014. The current practice is to favor the sternotomy approach (Figure E1).

\section{Operative Technique}

Arch and DTA replacement via thoracotomy (DTR

group). Surgical approach was achieved via left fourth or fifth thoracotomy with division of the costal margin in the fifth interspace. Left femoral artery and vein cannulations were routinely used to establish cardiopulmonary bypass (CPB). Left ventricle venting was achieved with the left low pulmonary vein or left ventricle apex. Total circulatory arrest was induced at a core body (bladder) temperature of $20^{\circ} \mathrm{C}$ without cerebral perfusion and cardioplegia. Body temperature of total circulatory arrest was determined with electroencephalograph monitoring. We routinely monitored the electroencephalograph and used bladder temperature to monitor core temperature for systemic organ protection.

Total arch replacement via median sternotomy (TAR group). Total arch and proximal DTA replacement via sternotomy was based on an antegrade cerebral perfusion and moderate cooling $\left(28^{\circ} \mathrm{C}\right)$ strategy. Femoral artery and right atrium cannulations were routinely used to establish $\mathrm{CPB}$, and right axillary cannulation was used for antegrade cerebral perfusion. Unilateral cerebral perfusion through the right axillary artery was performed by clamping the innominate artery, and bilateral cerebral perfusion was sometimes performed by inserting a 12-French balloon perfusion catheter into the left carotid artery when regional SO2 (rSO2) fell to less than 50\%. Distal anastomosis was first performed using 3-0 Prolene sutures after circulatory arrest. After systemic perfusion through the side branch of the graft was restored, the cerebral vessels and proximal aorta were reconstructed step-by-step (Video 1).

Hybrid arch repair (HAR group). The operation was performed using general endotracheal anesthesia with continuous monitoring using transesophageal echocardiogram, $\mathrm{rSO} 2$, and arterial pressure monitoring. Five patients $(12.8 \%)$ underwent the procedure in one stage, and 32 patients $(87.2 \%)$ underwent the procedure in 2 stages. In the cases of a 2-stage procedure, thoracic endovascular aortic repair (TEVAR) was performed after full recovery from cervical debranching. Complete debranching was performed through a median sternotomy. After induction of pharmacologic hypotension to a systolic blood pressure less than $90 \mathrm{~mm}$ $\mathrm{Hg}$, the ascending aorta was partially clamped with a side-biting clamp, and the proximal end of a prosthetic graft was sutured end-to-side to the aorta. The left subclavian artery (LSCA) was revascularized through the sternotomy without additional incisions. LSCA revascularization was performed if possible, but when it was difficult to expose, the LSCA was selectively ligated after confirming communication of the vertebral artery. Cervical debranching was performed through a cervicotomy and consisted of a supratracheal right carotid-to-left common carotid artery bypass using a Gore-Tex 8-mm graft or 8-mm Dacron graft. Carotid clamping was performed using rSO2 monitoring, and no cases required a carotid shunt. All TEVAR were performed in a hybrid room with both endovascular and surgical equipment.

\section{Endpoint and Definition}

The primary endpoints of this study were in-hospital, 30-day, and late mortality. Secondary endpoints were operative morbidities, including neurologic (stroke and spinal cord ischemia) and pulmonary complications and reintervention. In-hospital or 30-day mortality was defined as any death occurring within 30 days of the original procedure, or while the patient was still in the hospital. A reintervention was defined as any surgical or endovascular procedure for any complication related to the aorta after the primary procedure. Spinal cord ischemia was defined as any new lower-extremity deficit not related to an intracerebral event. Permanent spinal cord ischemia was diagnosed if symptoms were not completely resolved at the time of discharge. Stroke was defined as any new global or focal neurologic deficit lasting more than 24 hours with an acute lesion on brain imaging. 


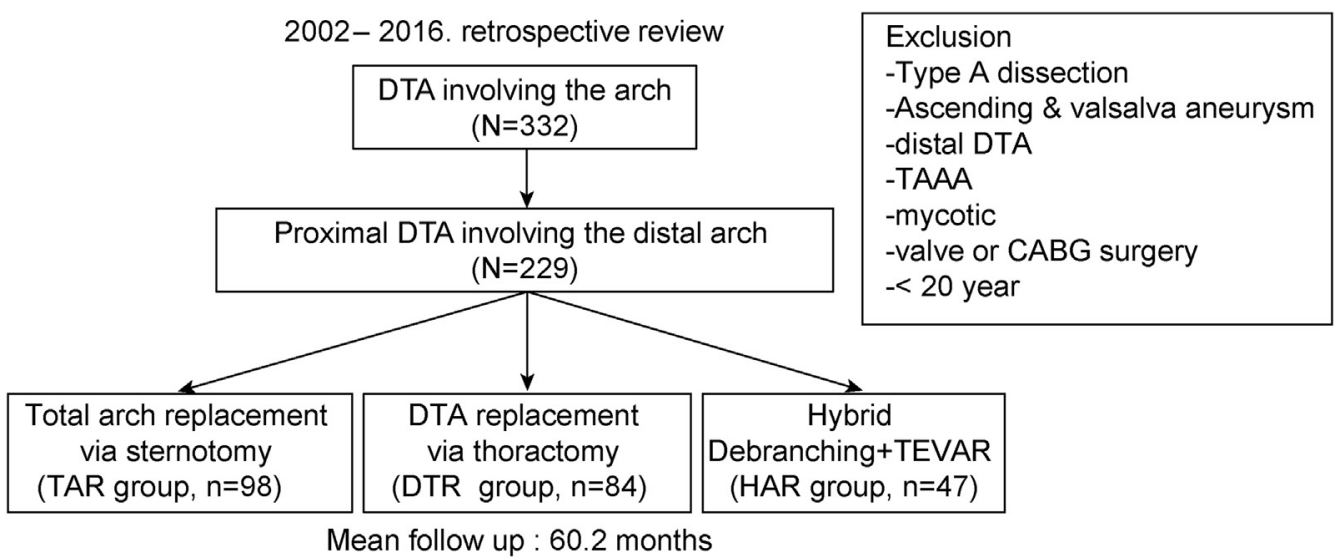

FIGURE 1. Current study cohort of 229 patients who underwent aortic repair for proximal descending aortic aneurysm involving the distal arch. DTA, Descending thoracic aneurysm; TAR, total arch and descending replacement via sternotomy; $D T R$, hemiarch and descending replacement via thoracotomy; $T E V A R$, thoracic endovascular aortic repair; HAR, hybrid arch repair; TAAA, thoracoabdominal aortic aneurysm; CABG, coronary artery bypass grafting.

\section{Data Collection and Follow-up}

Preoperative data and perioperative data were collected prospectively from the cardiac and vascular research databases at our institution. More detailed data for clinical outcomes and long-term survival were obtained by hospital chart review or telephone interview. Information on death was obtained by the database of the Korea National Statistical Office. Follow-up was complete for $97.8 \%$ of patients. Our study was conducted following approval by the Institutional Review Board of the Yonsei University College of Medicine. The individual patient consent was waived. Follow-up protocols included clinical examination and computed tomography scan before discharge, which was performed at 6 months and annually thereafter.

\section{Statistical Analyses}

The statistical analyses were performed with SPSS for Windows, Release 18.0 (SPSS, Chicago, Ill). All data were expressed as the

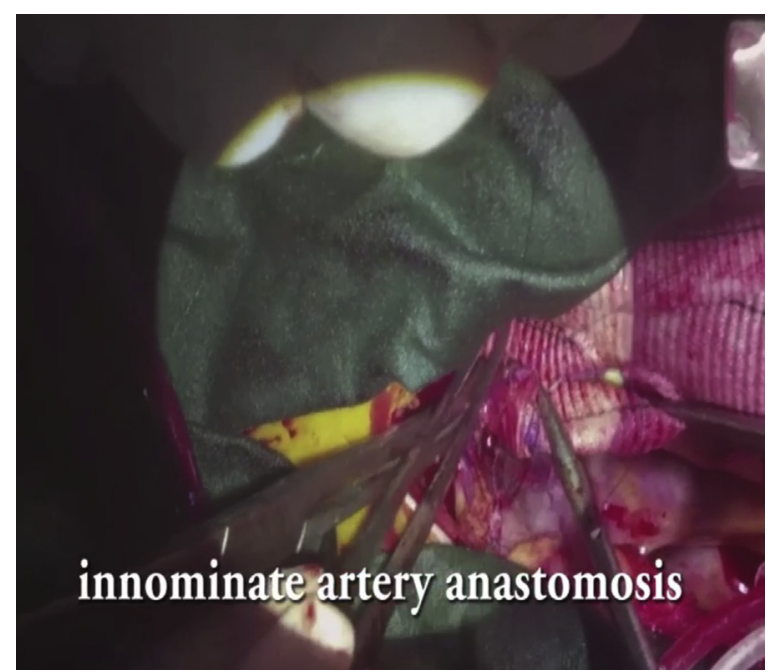

VIDEO 1. Sternotomy approach for proximal descending aneurysm involving the arch. Total arch and proximal descending aorta replacement was performed using right axillary cannulation, bilateral antegrade cerebral perfusion, mild hyperthermia $\left(28^{\circ} \mathrm{C}\right)$, and a 4-branched graft. Video available at: http://www.jtcvsonline.org/article/S0022-5223(18)30404-5/fulltext. mean \pm standard deviation, frequency, or percentage. Continuous variables were compared using a Student $t$ test and categorical variables were compared using the $\chi^{2}$ or Fisher exact test. Best fit was assessed using the Hosmer and Lemeshow $\chi^{2}$ test. A comparison among the three groups was performed using the Kruskal-Wallis test for continuous variables or the $\chi^{2}$ test for categorical variables. Long-term survival and freedom of reintervention curves were estimated using the Kaplan-Meier method. Binary logistic regression analysis was performed to identify independent risk factor of operative mortality and respiratory complication. Risk factors found on univariate analysis to have a value of $P<.1$ were included in the multivariable model. Multivariable Cox regression analysis was performed to identify independent predictor of long-term survival. Differences between curves were compared using the log-rank test. In all statistical tests, statistical significance was defined as a two-tailed $P<.05$.

\section{RESULTS}

\section{Patient Characteristics}

The patient demographics and clinical risk factors among the 3 groups are summarized in Table 1 . The patients in the HAR group were older than the other groups, but there was not a significant difference $(66.0 \pm 13.1$ vs $63.3 \pm 11.3$ vs $61.3 \pm 11.7 ; P=.08$ ). The hybrid group tended to have a higher proportion of coronary artery occlusive disease and chronic obstructive pulmonary disease than the other groups. No differences were observed between the groups in term of sex, smoking, hypertension, diabetes mellitus, chronic renal failure, left ventricular ejection fraction, and previous cerebrovascular incidents. Aortic pathologies, such as the maximal size of aneurysm, Marfan syndrome, and emergency, were similar among the 3 groups.

\section{Operative Data}

Operation time was significantly shorter in the HAR group than in the other groups. Antegrade cerebral perfusion was used for cerebral protection in most TAR patients and LSCA revascularization was performed at a high rate in this group compared with the other groups. The stent types used for TEVAR in the hybrid group included 18 Seal stents 
TABLE 1. Patient characteristics

\begin{tabular}{|c|c|c|c|c|}
\hline Variables & $\operatorname{TAR}(\mathbf{n}=98)$ & $\operatorname{DTR}(n=84)$ & HAR $(n=47)$ & $P$ value \\
\hline Age (y) & $63.3 \pm 11.3$ & $61.3 \pm 11.7$ & $66.0 \pm 13.1$ & .24 \\
\hline Male sex & $68(69.4)$ & $63(75.0)$ & $41(87.2)$ & .07 \\
\hline Smoking & $43(43.9)$ & $39(46.4)$ & $29(61.7)$ & .11 \\
\hline Hypertension & $74(75.5)$ & $60(71.4)$ & 37 (78.7) & .64 \\
\hline Diabetes & $12(12.2)$ & $11(13.1)$ & $6(12.8)$ & .99 \\
\hline CAOD & $27(27.6)$ & $24(28.6)$ & $20(42.6)$ & .16 \\
\hline Old CVA & $12(12.2)$ & $8(9.5)$ & $6(12.8)$ & .80 \\
\hline COPD & $8(8.2)$ & $5(6.0)$ & $8(17.0)$ & .09 \\
\hline $\operatorname{LVEF}(\%)$ & $60.6 \pm 5.8$ & $61.2 \pm 6.1$ & $60.3 \pm 5.6$ & .89 \\
\hline eGFR & $73.4 \pm 26.0$ & $72.9 \pm 28.3$ & $69.3 \pm 26.3$ & .67 \\
\hline Maximal aneurysm size $(\mathrm{cm})$ & $60.4 \pm 10.0$ & $60.8 \pm 13.7$ & $60.7 \pm 10.1$ & .99 \\
\hline Marfan syndrome & $8(8.2)$ & $10(11.9)$ & $4(8.5)$ & .68 \\
\hline Aortic pathology & & & & .41 \\
\hline Degenerative aneurysm & 77 (77.6) & $65(77.4)$ & $32(68.1)$ & \\
\hline Dissection & $22(22.4)$ & $19(22.6)$ & 15 (31.9) & \\
\hline Acute & $5(5.1)$ & $5(6.0)$ & $2(4.3)$ & .91 \\
\hline Chronic & $17(17.3)$ & $14(16.7)$ & $13(27.7)$ & .26 \\
\hline Extent of DTA & & & & .33 \\
\hline Subclavian $\sim$ T5 & $49(50.0)$ & $33(39.3)$ & $20(42.6)$ & \\
\hline $\mathrm{T} 5 \sim \mathrm{T} 7$ & $49(50.0)$ & $51(60.7)$ & $27(57.4)$ & \\
\hline Rupture & $6(6.1)$ & $5(6.0)$ & $2(4.3)$ & .89 \\
\hline Urgent, emergency & $16(16.3)$ & $11(13.1)$ & $2(4.3)$ & .12 \\
\hline
\end{tabular}

TAR, Total arch and DTA replacement via sternotomy; DTR, DTA replacement via thoracotomy; HAR, hybrid arch repair; $C A O D$, coronary artery occlusive disease; $C V A$, cerebrovascular accident; $C O P D$, chronic occlusive pulmonary disease; $L V E F$, left ventricular ejection fraction; $e G F R$, estimated glomerular filtration rate; DTA, desecending thoracic aneurysm; $T$, thoracic spine.

(S\&G Biotech, Seoul, Korea), 15 Valiant stents (Medtronic, Santa Rosa, Calif), 4 Captivia stents, 2 Zenith stents (Cook Medical, Bloomington, Ind), and 2 Cook TX2 devices (Cook Medical). The details of the comparative operative data are summarized in Table 2.

\section{Early Outcomes}

The in-hospital mortality rate was $3.1 \%(3 / 98)$ in the TAR group, $11.9 \%(10 / 84)$ in the DTR group, and $4.3 \%$ $(2 / 47)$ in the HAR group $(P=.04$; Figure $2, A)$. The TAR group had a lower incidence of stroke $(3.1 \%, 3 / 98)$ compared with the DTR $(13.1 \%, 11 / 84)$ and HAR $(10.6 \%, 5 / 47 ; P=.03)$ groups (Figure $2, B)$. The HAR group had a lower incidence of prolonged ventilation time $(6.4 \%, 3 / 47)$ compared with the TAR $(16.3 \%, 16 / 98)$ and DTR $(19.0 \%, 16 / 84)$ groups $(P=.14)$, but the incidence of tracheostomy was similar between the TAR $(5.1 \%$. $5 / 98)$ and HAR $(4.3 \%, 2 / 47)$ groups. Incidence of vocal cord palsy was higher in the TAR $(18.4 \%, 18 / 98)$ and DTR $(20.2 \%, 17 / 84)$ groups compared with the HAR group $(2.1 \%, 1 / 47 ; P=.02)$. The early outcomes are summarized in Table 3.

\section{Long-Term Survival}

The mean follow-up time was $60.4 \pm 24.5$ months (range, 1-175 months) and was not significantly different among the 3 groups $(65.16 \pm 54.3$ months in the TAR vs $55.16 \pm 41.38$ in the DTR vs $57.98 \pm 41.04$ months in the HAR groups; $P=.376$ ). The overall survival rate at 10 years was $82.8 \% \pm 5.6 \%$ in the TAR group, $61.0 \% \pm 8.6 \%$ in the DTR group, and $55.9 \% \pm 9.0 \%$ in the HAR group. The long-term survival in the TAR group was significantly greater compared with the other groups (vs DTR $[P=.03]$ vs HAR $[P<.01]$; Figure 3$)$, but there was no difference between the DTR and HAR groups $(P=.41$; Figure 3$)$.

\section{Late Aortic Events and Reintervention}

During the follow-up period, 7 late deaths occurred in the HAR group, 6 of which were aortic-related deaths or sudden deaths. In the TAR and DTR groups, aortic-related death or sudden death occurred in 3 patients. Four late strokes occurred in the DTR and HAR groups, and no late strokes occurred in the TAR group. Seven type I endoleak, 2 type II endoleak, 2 stent induced new entry tear, 2 retrograde 
TABLE 2. Operative data details

\begin{tabular}{|c|c|c|c|}
\hline Variables & TAR $(\mathbf{n}=98)$ & DTR $(n=84)$ & HAR $(n=47)$ \\
\hline Incision & Sternotomy & Thoracotomy & - \\
\hline CPB bypass & $\begin{array}{l}\text { Artery-axillary/femoral; } \\
\text { vein-right atrium }\end{array}$ & $\begin{array}{l}\text { Artery-left femoral; vein-left } \\
\text { femoral }\end{array}$ & - \\
\hline Total circulatory arrest & $98(100 \%)$ & $68(81.0 \%)$ & - \\
\hline Axillary C graft & $79(80.6 \%)$ & - & - \\
\hline Selective & $6(6.1 \%)$ & $13(19.1 \%)$ & - \\
\hline Retrograde & $13(13.2 \%)$ & - & - \\
\hline No cerebral perfusion & - & $55(80.8 \%)$ & - \\
\hline Mean TCA time & $53.5 \pm 31.4 \mathrm{~min}$ & $16.7 \pm 20.0 \mathrm{~min}$ & - \\
\hline Mean lowest time & $27.6 \pm 4.2^{\circ} \mathrm{C}$ & $22.4 \pm 4.6^{\circ} \mathrm{C}$ & - \\
\hline Mean CPB time & $191.2 \pm 71.3 \mathrm{~min}$ & $161.8 \pm 52.3 \mathrm{~min}$ & - \\
\hline Mean operative time & $312.1 \pm 88.3 \mathrm{~min}$ & $304.7 \pm 89.1 \mathrm{~min}$ & $189.6 \pm 76.2 \mathrm{~min}$ \\
\hline SCA sacrifice & $8(8.1 \%)$ & $10(11.9 \%)$ & $2(4.2 \%)$ \\
\hline Debranching & - & - & $27(57.4 \%)$ \\
\hline Carotid-carotid-SCA bypass & - & - & $11(23.4 \%)$ \\
\hline Carotid-carotid bypass & - & - & $2(4.2 \%)$ \\
\hline Carotid-SCA bypass & - & - & $6(12.7 \%)$ \\
\hline Carotid-SCA interposition & - & - & $1(2.1 \%)$ \\
\hline One stage & - & - & $6(12.7 \%)$ \\
\hline Staged procedure & - & - & $41(87.3 \%)$ \\
\hline
\end{tabular}

$\overline{T A R}$, Total arch and DTA replacement via sternotomy; DTR, DTA replacement via thoracotomy; $H A R$, hybrid arch repair; $C P B$, cardiopulmonary bypass; $T C A$, total circulatory arrest; $S C A$, subclavian artery.

type A dissection, and 1 stent migration occurred in the hybrid group. Fourteen $(31.1 \%)$ HAR patients underwent reintervention $(n=10)$ or surgery $(n=4)$ of open conversion. The freedom from late stroke at 10 years was $100 \%$ in the TAR group, $71.9 \pm 12.6$ in the DTR group, and $56.9 \% \pm 17.3 \%$ in the HAR group $(P<.01)$. The reintervention-free rate at 10 years was $87.9 \% \pm 5.7 \%$ in the TAR group, $82.1 \% \pm 10.1 \%$ in the DTR group, and $35.7 \% \pm 15.8 \%$ in the HAR group, and these rates were significantly different $(P<.01$; Figure $4, A)$. The freedom from composite of aortic events at 10 years was $75.6 \% \pm 8.1 \%$ in the TAR group, $43.6 \% \pm 14.9 \%$ in the DTR group, and $31.1 \% \pm 11.5 \%$ in the HAR group, and these rates were significantly different $(P<.01$; Figure $4, B)$.

\section{Predictors of Perioperative Mortality and Long- Term Survival}

The independent risk factors of operative mortality were age, lower estimated glomerular filtration rate, thoracotomy approach, CPB time (Table 4). In the Cox regression
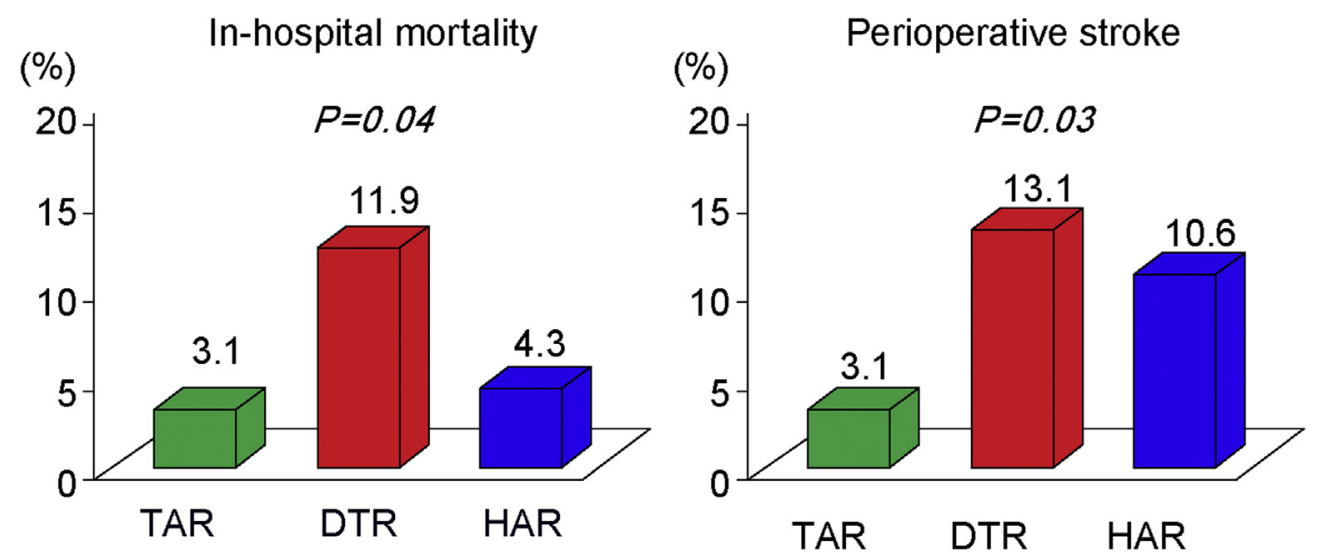

FIGURE 2. The comparison of in-hospital mortality and perioperative stroke rates among the 3 groups. TAR, Total arch and descending replacement via sternotomy; DTR, hemiarch and descending replacement via thoracotomy; HAR, hybrid arch repair. 
TABLE 3. Postoperative outcomes

\begin{tabular}{|c|c|c|c|c|}
\hline Variables & TAR $(\mathbf{n}=98)$ & $\operatorname{DTR}(n=84)$ & HAR $(n=47)$ & $P$ value \\
\hline In-hospital mortality & $3(3.1)$ & $10(11.9)$ & $2(4.3)$ & .04 \\
\hline Stroke & $3(3.1)$ & $11(13.1)$ & $5(10.6)$ & .03 \\
\hline Paraplegia & $1(1.0)$ & $2(2.4)$ & $0(0.0)$ & .49 \\
\hline Reoperation for bleeding & $9(9.2)$ & $5(6.0)$ & $2(4.3)$ & .49 \\
\hline Requirement for new dialysis & $5(5.1)$ & 9 (10.7) & $2(4.3)$ & .25 \\
\hline Tracheostomy & $5(5.1)$ & $15(17.9)$ & $2(4.3)$ & $<.01$ \\
\hline Ventilator duration $(>72 \mathrm{~h})$ & $16(16.3)$ & $16(19.0)$ & $3(6.4)$ & .14 \\
\hline Vocal cord palsy & $18(18.4)$ & $17(20.2)$ & $1(2.4)$ & .02 \\
\hline ICU stay $(\mathrm{d})$ & $5.9 \pm 9.4$ & $9.0 \pm 17.9$ & $4.4 \pm 9.4$ & .11 \\
\hline Hospital stay (d) & $19.6 \pm 21.8$ & $24.9 \pm 29.5$ & $21.5 \pm 47.2$ & .51 \\
\hline
\end{tabular}

TAR, Total arch and DTA replacement via sternotomy; DTR, DTA replacement via thoracotomy; $H A R$, hybrid arch repair; ICU, intensive care unit.

multivariate analysis, age, female sex, and chronic kidney disease were independent risk factors of overall survival, and sternotomy approach was an independent predictor for better overall survival (Table 5).

\section{COMMENTS}

Although 3 approaches (sternotomy, thoracotomy, hybrid) for proximal descending thoracic aortic pathologies involving the distal arch have been applied, the best option is not well defined. The current study is unique in its comparison and analysis of early and late outcomes of the 3 different approaches. This study demonstrates that compared with thoracotomy or hybrid approaches, a sternotomy approach

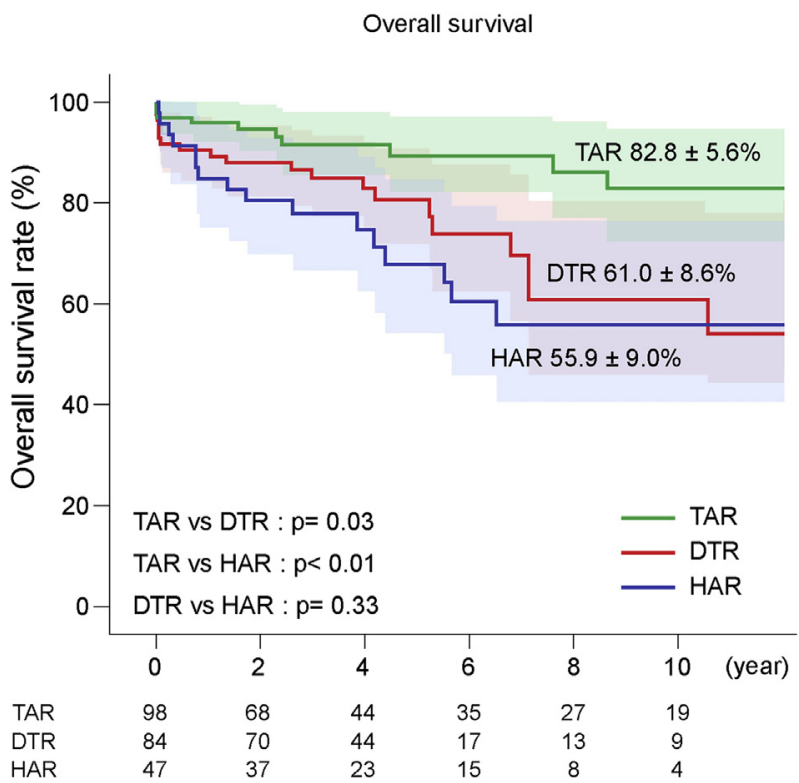

FIGURE 3. Kaplan-Meier curves comparing the overall survival rate of the three groups. TAR, Total arch and descending replacement via sternotomy; DTR, hemiarch and descending replacement via thoracotomy; HAR, hybrid arch repair. has better outcomes in terms of operative mortality, stroke, and long-term survival and aortic events.

\section{Early Outcomes (Mortality and Morbidities) of the Three Approaches}

The DTR group (11.9\%) had higher incidence of operative mortality compared with the other groups (TAR, $3.1 \%$; HAR, $4.3 \%$ ). The DTR group had more perioperative mortality from embolic events and pulmonary complications compared with the other groups. Four patients died from a major stroke, and one patient died from a myocardial infarction caused by a coronary embolism owing to retrograde input of arch debris. Three patients died of sepsis from pulmonary complications. Although clinical outcome of open repair for isolated DTA has been reported, the outcome of thoracotomy approach for DTA involving the distal arch has not been well documented. Contemporary data from large-volume aortic centers showed mortality rate of $7 \%$ to $9 \%{ }^{7,8}$ Okita et $\mathrm{al}^{9}$ emphasized that a strong factor that affects early morality and stroke rate is involvement of the atherosclerotic arch lesion in the descending thoracic aneurysm. We found that many causes of early mortality in the DTR group were associated with manipulation of the arch lesion. These findings demonstrate that when the arch lesion is involved, the thoracotomy approach has many potential risks, such as embolic events or lung complications that can be associated with perioperative mortality.

In contrast, the TAR group had a similar early mortality rate compared with the HAR group $(3.1 \%$ vs $4.3 \%)$ ). This outstanding result is consistent with current outcomes of reports from the last few years. A meta-analysis from Fabrizio and colleagues, ${ }^{10}$ which included 21 reports published between 2004 and 2014, demonstrated that total arch replacement has dramatically improved surgical mortality (mean $5.3 \%) .{ }^{10}$ These findings imply that it is difficult to conclude that the hybrid procedure has a definite superiority compared with total arch replacement, even regarding perioperative mortality. 

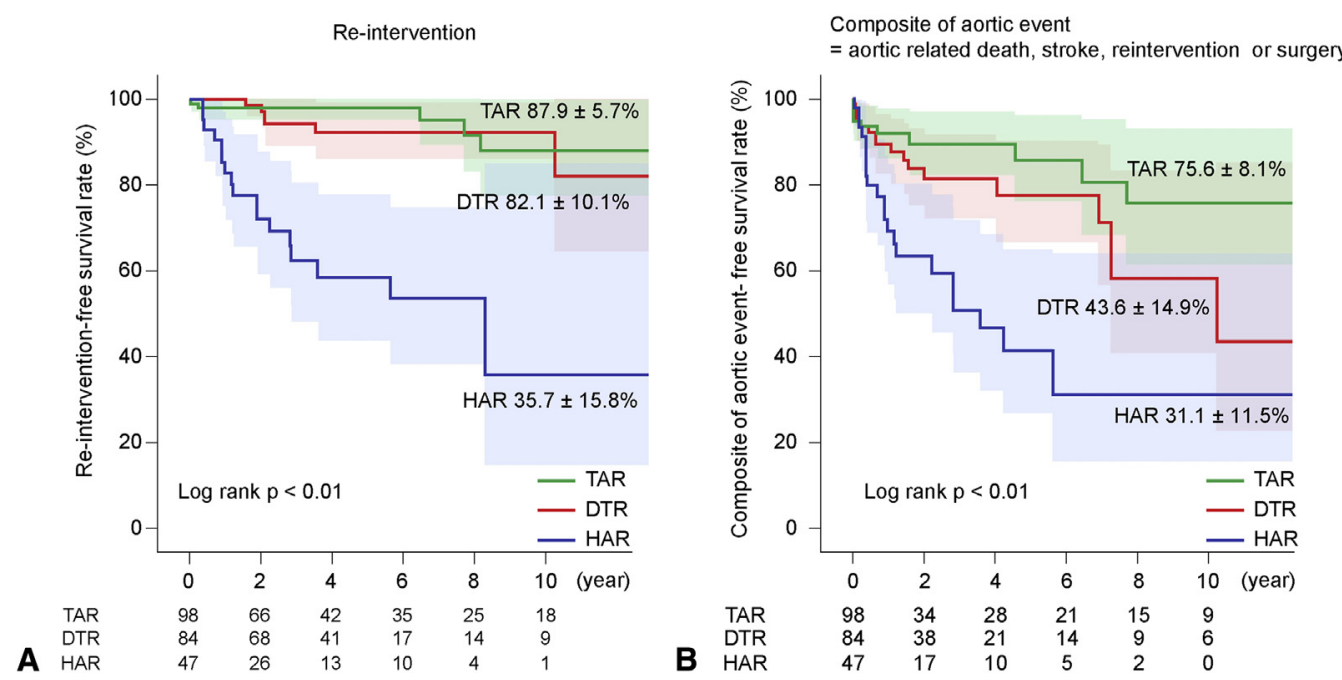

FIGURE 4. Kaplan-Meier curves comparing (A) the reintervention-free survival rate and (B) the composite of aortic event (aortic-related death, stroke, reintervention, or surgery)-free survival rate among the 3 groups. TAR, Total arch and descending replacement via sternotomy; DTR, hemiarch and descending replacement via thoracotomy; HAR, hybrid arch repair.

In terms of morbidities and early recovery, the hybrid technique had better outcomes than open repair did. According to published data, hybrid arch repair seems to have more favorable results for operative morbidities and early recovery compared with open repair. ${ }^{11,12}$ Our study also showed that patients who underwent the hybrid

TABLE 4. Binary logistic regression model for operative mortality

\begin{tabular}{|c|c|c|c|c|}
\hline \multirow[b]{2}{*}{ Variables } & \multicolumn{2}{|c|}{ Univariate } & \multicolumn{2}{|c|}{ Multivariate } \\
\hline & OR $(95 \%$ CI $)$ & $P$ value & OR $(95 \% \mathrm{CI})$ & $P$ value \\
\hline Age & $1.070(1.011-1.131)$ & .02 & $1.137(0.997-1.273)$ & .04 \\
\hline Female sex & $2.803(0.614-0.753)$ & .14 & & \\
\hline Smoking & $2.929(0.891-9.630)$ & .08 & & \\
\hline Hypertension & $5.032(0.644-39.312)$ & .12 & & \\
\hline Diabetes & $1.212(0.257-5.720)$ & .81 & & \\
\hline CAOD & $4.442(1.432-13.783)$ & .01 & & \\
\hline Old CVA & $0.397(0.103-1.537)$ & .18 & & \\
\hline COPD & $2.277(0.591-8.763)$ & .23 & & \\
\hline $\operatorname{LVEF}(\%)$ & $1.821(0.782-3.341)$ & .44 & & \\
\hline eGFR & $0.950(0.928-0.974)$ & $<.01$ & $0.952(0.925-0.980)$ & $<.01$ \\
\hline Maximal aneurysm size & $1.044(0.998-1.091)$ & .06 & & \\
\hline Marfan syndrome & $0.311(0.021-2.157)$ & .99 & & \\
\hline Dissection & $1.452(0.441-4.784)$ & .54 & & \\
\hline \multicolumn{5}{|l|}{ Extent of DTA } \\
\hline T7 vs T5 & $1.781(0.591-4.691)$ & .15 & & \\
\hline Urgent, emergency & $2.702(0.343-21.298)$ & .35 & & \\
\hline \multicolumn{5}{|l|}{ Surgery type } \\
\hline DTR vs TAR & $3.800(0.994-14.531)$ & .05 & $5.112(1.152-23.681)$ & .03 \\
\hline HAR vs TAR & $1.407(0.277-8.721)$ & .71 & & \\
\hline CPB time & $1.003(0.997-1.009)$ & .32 & $1.007(1.001-1.013)$ & .02 \\
\hline
\end{tabular}

$\overline{O R}$, Odds ratio; $C I$, confidence interval; $C A O D$, coronary artery occlusive disease; $C V A$, cerebrovascular accident; $C O P D$, chronic occlusive pulmonary disease; $L V E F$, left ventricular ejection fraction; $e G F R$, estimated glomerular filtration rate; $D T A$, descending thoracic aneurysm; $T$, thoracic spine; $D T R$, DTA replacement via thoracotomy; $T A R$, total arch and DTA replacement via sternotomy; $H A R$, hybrid arch repair; $C P B$, cardiopulmonary bypass. 
TABLE 5. Cox regression analysis on overall survival

\begin{tabular}{|c|c|c|c|c|}
\hline \multirow[b]{2}{*}{ Variables } & \multicolumn{2}{|c|}{ Univariate } & \multicolumn{2}{|c|}{ Multivariate } \\
\hline & HR $(95 \%$ CI $)$ & $P$ value & HR $(95 \%$ CI $)$ & $P$ value \\
\hline Age (y) & $1.070(1.048-1.1110)$ & $<.01$ & $1.060(1.021-1.100)$ & $<.01$ \\
\hline Female gender & $5.829(1.806-18.813)$ & .03 & 3.795 (1076-13.387) & .04 \\
\hline Smoking & $2.020(1.117-3.653)$ & .02 & & \\
\hline Hypertension & $1.807(0.871-3.749)$ & .11 & & \\
\hline Diabetes mellitus & $2.325(1.116-4.843)$ & .02 & & \\
\hline CAOD & $2.251(1.404-4.483)$ & $<.01$ & & \\
\hline Old CVA & $1.666(0.705-3.938)$ & .25 & & \\
\hline COPD & $2.295(1.390-6.152)$ & $<.01$ & & \\
\hline LVEF \% & $2.134(0.691-2.624)$ & .21 & & \\
\hline Chronic renal failure & $4.062(0.254-7.320)$ & $<.01$ & $4.185(1.120-4.320)$ & .02 \\
\hline Maximun aortic size & $1.032(1.009-1.055)$ & .09 & & \\
\hline Marfan syndome & $1.451(0.431-2.224)$ & .11 & & \\
\hline Dissection & $2.281(1.171-4.442)$ & .02 & & \\
\hline \multicolumn{5}{|l|}{ Distal extent } \\
\hline T7 vs T5 & $2.213(0.781-4.012)$ & .23 & & \\
\hline Ugent/emergency & $0.579(0.245-1.372)$ & .22 & & \\
\hline \multicolumn{5}{|l|}{ Surgery type } \\
\hline DTR vs TAR & $2.246(1.054-4.739)$ & .03 & $2.208(1.009-4.831)$ & .03 \\
\hline HAR vs TAR & $3.187(1.474-6.891)$ & $<.01$ & $2.120(1.002-4.919)$ & .04 \\
\hline CPB time & $0.99(0.995-1.003)$ & .69 & & \\
\hline
\end{tabular}

$\overline{H R}$, Hazard ratio; $C I$, confidence interval; $C A O D$, coronary artery occlusive disease; $C V A$, cerebrovascular accident; $C O P D$, chronic occlusive pulmonary disease; $L V E F$, left ventricular ejection fraction; $T$, thoracic spine; DTR, DTA replacement via thoracotomy; TAR, total arch and DTA replacement via sternotomy; HAR, hybrid arch repair; $C P B$, cardiopulmonary bypass.

technique had reduced pulmonary and renal complications and shorter intensive care unit and hospital stays. One interesting finding from this study is that, in contrast with the DTR group, the TAR group was not worse than the hybrid group in terms of fatal complications, such as perioperative stroke, requirement for new dialysis, or tracheostomy. These findings suggest that the sternotomy approach is safer than thoracotomy in terms of unavoidable damage for patients who undergo major open surgery.

\section{Advantage of Sternotomy Approach for Stroke Events}

Although there are many studies of the decreased invasiveness of hybrid arch repair, ${ }^{11,12}$ there is not much research successfully demonstrating the superiority of the hybrid technique for perioperative stroke compared with conventional open repair. Application of an endovascular procedure for arch lesions using the hybrid approach still has unavoidable risk for stroke because the aortic arch has unfavorable characteristics, including shape of angulation, high blood flow, and substantial pulsatile movement. When these characteristics are combined with an atherosclerotic arch lesion, a catheter procedure through the arch lesion can lead to an embolic event or dissection. In a meta-analysis, Moulakakis et $\mathrm{al}^{13}$ reported that hybrid arch repair still had a high stroke rate $(7.6 \%)$ and emphasized that this incidence was not lower than open repair.

The thoracotomy approach also has a danger of inducing embolic events. In case of arch clamping, manipulation of the aortic arch with the atherosclerotic lesion is inevitably required, which can lead to embolic stroke. In cases of deep hypothermic arrest without aortic clamping, when the arch is opened, the embolic burden in the atherosclerotic arch can fall into carotid vessels in a retrograde fashion, which can also lead to an embolic stroke. ${ }^{14}$ In contrast, the total arch approach via sternotomy has 2 advantages in terms of embolic events. First, when axillary antegrade cerebral perfusion is applied, manipulation of the arch lesion can be avoided. Second, there is no possibility of retrograde inflow of embolic debris into the carotid vessel with this procedure. Our study showed that the hybrid approach has reduced pulmonary and renal complications and reduced length of intensive care unit and hospital stays, but it did not have a benefit for perioperative stroke compared with conventional open repair. The sternotomy 
approach had a strong benefit for reducing the incidence of perioperative stroke compared with the other approaches.

Another significant finding from our study is that the sternotomy approach had an advantage in terms of late stroke. During the mean 43-month follow-up period, late strokes occurred in 5.4\% (4/74) of patients from the DTR group and $8.9 \%(4 / 45)$ of patients from the HAR group. Importantly, no patients experienced late stroke in the TAR group. This shows that the TAR strategy has great advantages in terms of preventing late stroke events, which may be due to complete removal of atherosclerotic lesions upon TAR, whereas these lesions partially remain in patients who undergo thoracotomy or the hybrid approach.

\section{Pulmonary Complications With the Thoracotomy Approach}

Pulmonary complication is the most common postoperative complication of aortic arch repair, and it is reported to be as high as $30 \% .^{15}$ In our study, the hybrid group had far fewer occurrences of pulmonary complications compared to the other groups. The requirement of prolonged mechanical ventilation and tracheostomy were more frequent in the DTR group compared with the other groups. It is thought that the thoracotomy approach often requires lung manipulation and causes lung bleeding and edema. In addition, thoracotomy pain often disturbs bronchial toilet. An interesting finding was that the thoracotomy approach had a significantly higher incidence of tracheostomy (16.7\%), but the sternotomy approach and hybrid approach showed a similar incidence $(5.1 \%$ vs $4.3 \%)$. Because TAR patients do not experience thoracotomy pain and lung manipulation, which have detrimental effects on recovery of lung function, the TAR group showed comparable results in terms of severe lung complications, such as tracheostomy.

\section{Achilles Heel of Hybrid Strategies: Reintervention and Late Event}

It is well known that reintervention after endovascular aortic repair occurs more often than after open repair. The reintervention rate of hybrid arch repair varies from $0 \%$ to $30 \%{ }^{16-20}$ In the current study, the hybrid approach had a higher rate of reintervention and late aortic events than the other approaches (Figure 4). Fourteen $(31.1 \%$ ) patients in the hybrid group underwent reintervention or open surgery for various causes, including endoleak, new dissection, stent migration, and infection. The most common cause of reintervention was type I endoleak. It is thought that characteristics of the arch associated with angulation, high blood flow, and substantial pulsatile movement, as mentioned earlier, can contribute to the development of type I endoleak, thus leading to reintervention or conversion. In freedom from composite of aortic events during the 10year follow-up, patients in the HAR group had a significant disadvantage compared with those who underwent open repair $(P<.01)$. An important point to note from the current study is that late complications after hybrid arch repair can occur at various times after the initial procedure and can lead to a fatal condition. Many late complications of hybrid arch repair can be resolved with endovascular surgery; however, patients who lack other options for endovascular salvage may need to undergo open conversion, which carries a risk of sudden death. These findings suggest that the long-term survival of hybrid arch repair could decrease over time. The HAR group had a significantly higher reintervention rate, which is not surprising compared with open surgical techniques, but a significantly higher late mortality $(P<.01)$; this suggests that hybrid approach might be an inadequate treatment of the aortic pathology involving the arch.

\section{Limitations}

This study had several limitations. First, this study is limited by the nature of retrospective studies, including an intrinsic selection bias and lack of a matched comparison group. Second, factors such as surgeon experience and the time the procedure is performed could influence outcomes. Third, this study is limited by the heterogeneity of patients, including patient characteristics, aortic pathology, and extent of involvement. Nevertheless, we minimized the heterogeneity associated with extent of involvement by focusing on DTA involving the distal arch. Finally, the study was also limited by the relatively small number of patients.

\section{CONCLUSIONS}

For the treatment of aortic pathologies with proximal DTA involving the distal arch, the TAR approach had better outcomes in terms of operative mortality and stroke and long-term survival compared with the thoracotomy or hybrid approaches. Hybrid repair remains controversial regarding perioperative stroke and long-term durability. Our results suggest that the sternotomy approach is the superior option for patients with proximal DTA involving the distal arch.

\section{Conflict of Interest Statement}

Authors have nothing to disclose with regard to commercial support.

\section{References}

1. Kay GL, Cooley DA, Livesay JJ, Reardon MJ, Duncan JM. Surgical repair of aneurysms involving the distal aortic arch. J Thorac Cardiovasc Surg. 1986;91: 397-404.

2. Patel HJ, Williams DM, Upchurch GR, Shillingford MS, Dasika NL, Proctor MC, et al. Long-term results from a 12-year experience with endovascular therapy for thoracic aortic disease. Ann Thorac Surg. 2006;82:2147-53.

3. Ogino H, Ando M, Sasaki H, Minatoya K. Total arch replacement using a stepwise distal anastomosis for arch aneurysms with distal extension. Eur J Cardiothorac Surg. 2006;29:255-7.

4. Kieffer E, Koskas F, Walden R, Godet G, Leblevec D, Bahnini A, et al. Hypothermic circulatory arrest for thoracic aneurysmectomy through left-sided thoractomy. J Vasc Surg. 1994;19:457-64. 
5. Kawaharada N, Kurimoto Y, Ito T, Koyanagi T, Yamauchi A, Nakamura M, et al. Hybrid treatment for aortic arch and proximal descending thoracic aneurysm: experience with stent grafting for second-stage elephant trunk repair. Eur J Cardiothorac Surg. 2009;36:956-61.

6. Geisbüsch P, Kotelis D, Müller-Eschner M, Hyhlik-Dürr A, Böckler D. Complications after aortic arch hybrid repair. J Vasc Surg. 2011:53:935-41.

7. Safi HJ, Miller CC, Subramaniam MH, Campbell MP, Iliopoulos DC, O'Donnell JJ, et al. Thoracic and thoracoabdominal aortic aneurysm repair using cardiopulmonary bypass, profound hypothermia, and circulatory arrest via left side of the chest incision. $J$ Vasc Surg. 1998;28:591-8.

8. Patel HJ, Shillingford MS, Mihalik S, Proctor MC, Deeb GM. Resection of the descending thoracic aorta: outcomes after use of hypothermic circulatory arrest. Ann Thorac Surg. 2006;82:90-6.

9. Okita Y, Ando M, Minatoya K, Kitamura S, Takamoto S, Nakajima N. Predictive factors for mortality and cerebral complications in arteriosclerotic aneurysm of the aortic arch. Ann Thorac Surg. 1999;67:72-8.

10. Settepani F, Cappai A, Basciu A, Barbone A, Tarelli G. Outcome of open total arch replacement in the modern era. J Vasc Surg. 2016;63:537-45.

11. Murashita T, Matsuda H, Domae K, Iba Y, Tanaka H, Sasaki H, et al. Less invasive surgical treatment for aortic arch aneurysms in high-risk patients: a comparative study of hybrid thoracic endovascular aortic repair and conventional total arch replacement. J Thorac Cardiovasc Surg. 2012;143:1007-13.

12. Gottardi R, Seitelberger R, Zimpfer D, Lammer J, Wolner E, Czerny M, et al. An alternative approach in treating an aortic arch aneurysm with an anatomic variant by supraaortic reconstruction and stent-graft placement. J Vasc Surg. 2005;42:357-60.

13. Moulakakis KG, Mylonas SN, Markatis F, Kotsis T, Kakisis J, Liapis CD. A systematic review and meta-analysis of hybrid aortic arch replacement. Ann Cardiothorac Surg. 2013;2:247-60.
14. Yoo JS, Kim JB, Jung SH, Choo SJ, Chung CH, Lee JW. Surgical repair of descending thoracic and thoracoabdominal aortic aneurysm involving the distal arch: open proximal anastomosis under deep hypothermia versus arch clamping technique. J Thorac Cardiovasc Surg. 2014;148: 2101-7.

15. Schechter MA, Shah AA, Englum BR, Williams JB, Ganapathi AM, Davies JD, et al. Prolonged postoperative respiratory support after proximal thoracic aortic surgery: Is deep hypothermic circulatory arrest a risk factor? J Crit Care. 2016; 31:125-9.

16. Lee WA. Failure modes of thoracic endografts: prevention and management. J Vasc Surg. 2009:49:792-9.

17. LeMaire SA, Green SY, Kim JH, Sameri A, Parenti JL, Lin PH, et al. Thoracic or thoracoabdominal approaches to endovascular device removal and open aortic repair. Ann Thorac Surg. 2012;93:726-33.

18. Canaud L, Alric P, Gandet T, Albat B, Marty-Ané C, Berthet JP, et al. Surgical conversion after thoracic endovascular aortic repair. J Thorac Cardiovasc Surg. 2011;142:1027-31.

19. Girdauskas E, Falk V, Kuntze T, Borger MA, Schmidt A, Scheinert D, et al. Secondary surgical procedures after endovascular stent grafting of the thoracic aorta: successful approaches to a challenging clinical problem. J Thorac Cardiovasc Surg. 2008;136:1289-94.

20. Szeto WY, Desai ND, Moeller PM, Moser GW, Woo EY, Fairman RM, et al. Reintervention for endograft failures after thoracic endovascular aortic repair. $J$ Thorac Cardiovasc Surg. 2013;145:S165-70.

Key Words: proximal descending, aneurysm, distal arch, different approaches 


\section{Trend of surgery type}

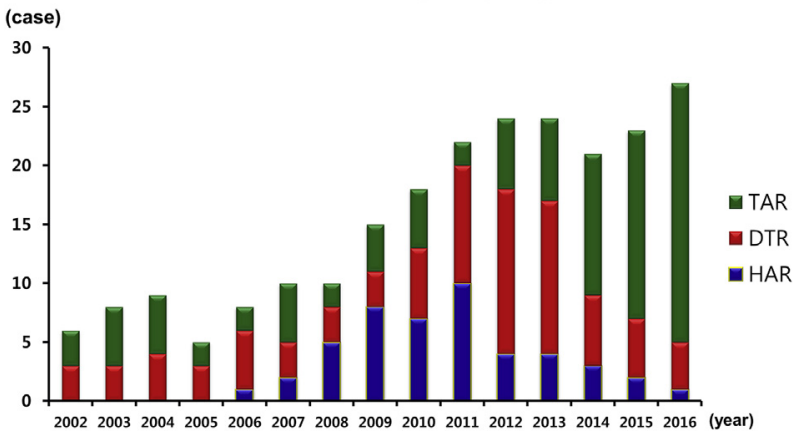

FIGURE E1. The change of distribution of 3 surgery types from 2002 to 2016. TAR, Total arch and descending thoracic aneurysm (DTA) replacement via sternotomy; DTR, DTA replacement via thoracotomy; HAR, hybrid arch repair.

TABLE E1. Subgroup analysis of DTR and HAR groups

\begin{tabular}{|c|c|c|c|c|c|c|}
\hline \multirow[b]{2}{*}{ Variables } & \multicolumn{3}{|c|}{ DTR group } & \multicolumn{3}{|c|}{ HAR group } \\
\hline & $\begin{array}{l}\text { Circulatory arrest } \\
(n=68)\end{array}$ & $\begin{array}{l}\text { Arch clamping } \\
\quad(\mathrm{n}=16)\end{array}$ & $P$ value & $\begin{array}{c}\text { Sternotomy } \\
\text { debranching }(n=27)\end{array}$ & $\begin{array}{c}\text { Cervical } \\
\text { debranching }(n=20)\end{array}$ & $P$ value \\
\hline In-hospital mortality & $9(13.2 \%)$ & $1(6.3 \%)$ & .44 & $1(3.7 \%)$ & $1(5 \%)$ & .83 \\
\hline Perioperative stroke & $9(13.2 \%)$ & $2(12.5 \%)$ & .94 & $3(11.1 \%)$ & $2(10 \%)$ & .90 \\
\hline
\end{tabular}

$D T R$, Hemiarch and descending replacement via thoracotomy; HAR, hybrid arch repair.

TABLE E2. Binary logistic regression model for respiratory complication

\begin{tabular}{|c|c|c|c|c|}
\hline \multirow[b]{2}{*}{ Variables } & \multicolumn{2}{|c|}{ Univariate } & \multicolumn{2}{|c|}{ Multivariate } \\
\hline & OR $(95 \%$ CI $)$ & $P$ value & OR $(95 \%$ CI $)$ & $P$ value \\
\hline Age & $1.039(1.002-1.078)$ & .03 & $1.161(1.097-1.218)$ & .02 \\
\hline Female sex & $1.833(0.600-5.603)$ & .29 & & \\
\hline Smoking & $2.409(0.987-5.878)$ & .05 & & \\
\hline Hypertension & $1.151(0.453-2.928)$ & .076 & & \\
\hline Diabetes & $3.608(1.342-9.702)$ & .01 & & \\
\hline CAOD & $2.045(0.868-4.820)$ & .10 & & \\
\hline Old CVA & $0.0756(0.166-3.435)$ & .72 & & \\
\hline COPD & $3.083(1.098-8.660)$ & .03 & $3.521(1.078-7.131)$ & .02 \\
\hline $\operatorname{LVEF}(\%)$ & $0.872(0.682-1.321)$ & .89 & & \\
\hline eGFR & $0.977(0.962-0.993)$ & $<.01$ & & \\
\hline Maximal aneurysm size $(\mathrm{cm})$ & $1.052(1.015-1.090)$ & $<.01$ & & \\
\hline Marfan syndrome & $0.402(0.052-3.138)$ & .38 & & \\
\hline Dissection & $1.805(0.687-4.743)$ & .23 & & \\
\hline \multicolumn{5}{|l|}{ Extent of DTA } \\
\hline T7 vs T5 & $1.605(0.785-3.879)$ & .11 & & \\
\hline Urgent, emergency & $1.372(0.478-3.932)$ & .55 & & \\
\hline \multicolumn{5}{|l|}{ Surgery type } \\
\hline DTR vs TAR & $4.376(1.529-12.528)$ & $<.01$ & $4.581(1.499-14.002)$ & $<.01$ \\
\hline HAR vs TAR & $1.268(0.290-5.547)$ & .75 & & \\
\hline CPB time & $1.008(1.002-1.014)$ & .01 & $1.007(1.001-1.013)$ & .02 \\
\hline
\end{tabular}

$O R$, Odds ratio; $C I$, confidence interval; $C A O D$, coronary artery occlusive disease; $C V A$, cerebrovascular accident; $C O P D$, chronic occlusive pulmonary disease; $L V E F$, left ventricular ejection fraction; $e G F R$, estimated glomerular filtration rate; $D T A$, descending thoracic aorta aneurysm; $T$, thoracic spine; $D T R$, DTA replacement via thoracotomy; TAR, total arch and DTA replacement via sternotomy; $H A R$, hybrid arch repair; $C P B$, cardiopulmonary bypass. 